\title{
PATIENTS TREATED WITH TRANSCUTANEOUS PULSED RADIOFREQUENCY IN PAINFULL KNEE, SEVERAL CASE REPORTS
}

\section{MB Rodríguez-Campoó}

\section{Background and Aims:}

Pulsed radiofrequency is the application of a high-frequency current with microseconds pause. This modality is a non-invasive one and it does not produce pain.

\section{Methods:}

We describe 3 cases of knee pain in elderly patients where the Surgery had been dismissed. We measured the efficacy in reducing the pain and how long did it last.
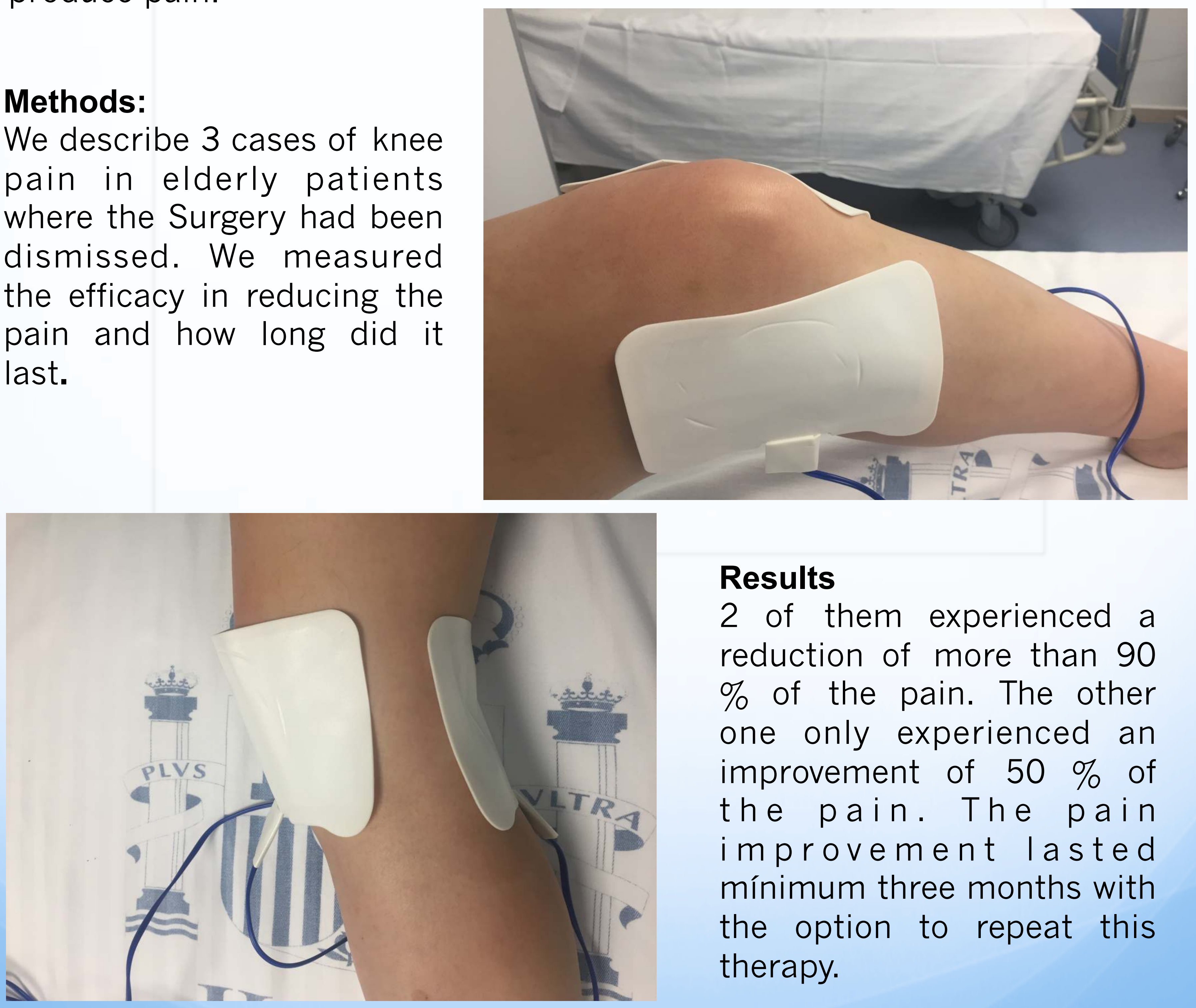

\section{Results}

2 of them experienced a reduction of more than 90 $\%$ of the pain. The other one only experienced an improvement of $50 \%$ of the pain. The pain improvement lasted mínimum three months with the option to repeat this therapy.

\section{Conclusions:}

Transcutaneous pulsed radiofrequency can be a non-invasive treatment for the painful knee with a high effectivity. More research might be conducted. 